\title{
AC 2011-41: DEVELOPING AN INSTRUMENT TO MEASURE THE IM- PACT OF SERVICE ON TECHNICAL AND PROFESSIONAL LEARNING OUTCOMES
}

\section{Adam R. Carberry, Arizona State University}

Adam R. Carberry received his PhD. in Engineering Education from the Tufts University Math, Science, Technology,and Engineering Education program in 2010. He holds an M.S. in Chemistry from Tufts University and a B.S. in Material Science Engineering from Alfred University. He is currently working as a Postdoctoral Research Associate in the College of Technology and Innovation, Department of Engineering at Arizona State University investigating engineering student conceptions of modeling.

\section{Christopher W. Swan, Tufts University}

Chris Swan is an associate professor of Civil and Environmental Engineering with additional affiliations with the Jonathan M. Tisch College of Citizenship and Public Service and the Center for Engineering Education and Outreach at Tufts University. Dr. Swan has also served as chair of Tufts CEE department (2002-2007) and as an officer in the Environmental Engineering division of ASEE (2001-2005). Dr. Swan's current interests lie in the areas of waste reuse, and service-based educational efforts in the engineering curriculum. Synergies of these efforts progressed to research on engineering education and training utilizing project-based learning and service-based pedagogies specifically their potential impacts on student learning and how these impacts may be evaluated and assessed. 


\title{
Developing an Instrument to Measure the Impact of Service on Technical and Professional Learning Outcomes
}

\begin{abstract}
Service experiences have seen a rise in engineering programs across the country. The increase in popularity was used as an impetus for the development of an instrument that measured student perceptions of service as a source of learning technical and professional skills. A previously developed instrument used to measure interventional impacts on engineering learning outcomes was modified to assess service's relative impact compared to traditional coursework learning. A 16-item validated instrument was developed. Results from the sample of students with service experiences identified a perception that 34 percent of what they learned about technical skills and 45 percent of what they learned about professional skills was learned through their service activity.
\end{abstract}

\section{Introduction}

Most engineering programs across the United States offer some sort of service experience for their students. In many instances these opportunities are presented as in-class service-learning courses. Others offer less formal, extracurricular programs like Engineers Without Borders (EWB). The combined availability and interest of in-class and extracurricular service begs the question of what participating students are gaining from such experiences. Anecdotally, professors and students alike claim the whole of these experiences as being great hands-on and real world learning opportunities. What is exactly learned is up for debate, especially given the massive variety of offerings.

This research was conducted to develop an instrument capable of measuring perceived impacts of any service experience on technical and professional learning outcomes. Traditional achievement assessments were identified as an inappropriate indicator because of the variety of service opportunities that exist and the numerous other experiences students have while participating in service. Instead we focus on student perceptions to obtain a measurement and understanding of what the specific intervention of interest, service, is providing. An effort was made to not differentiate between the different experiences so as to create an instrument that analyzes the impact of any type of service.

This paper includes a literature review and description of an instrument used to measure engineering learning outcomes. The design of our instrument is then discussed followed by the results of our development and implementation. We conclude with a short discussion and conclusion on the implications and possible future uses of our instrument.

\section{Literature Review}

Engineering institutions have many desired learning outcomes or skills they expect students to learn through undergraduate and graduate level education. ABET, formerly the Accreditation Board for Engineering and Technology, Criterion 3 outcomes a-k recommend that engineering programs must demonstrate that their graduates have: 
(a) an ability to apply knowledge of mathematics, science, and engineering,

(b) an ability to design and conduct experiments, as well as to analyze and interpret data,

(c) an ability to design a system, component, or process to meet desired needs,

(d) an ability to function on multidisciplinary teams,

(e) an ability to identify, formulate, and solve engineering problems,

(f) an understanding of professional and ethical responsibility,

(g) an ability to communicate effectively,

(h) the broad education necessary to understand the impact of engineering solutions in a global and societal context,

(i) a recognition of the need for, and ability to engage in, lifelong learning,

(j) a knowledge of contemporary issues,

(k) an ability to use the techniques, skills, and modern engineering tools necessary for engineering practice. ${ }^{1}$

Additional learning outcomes were suggested in the 2005 report from the National Academy of Engineering Center for the Advancement of Scholarship on Engineering Education (NAE CASEE). ${ }^{2}$ The report mentions that the engineering education community emphasizes:

(1) an ability to manage a project, including a familiarity with business, market-related, and financial matters,

(m) a multidisciplinary systems perspective,

(n) an understanding of and appreciation for the diversity of students, faculty, staff, colleagues, and customers, and

(o) a strong work ethic.

An ideal analysis of student learning should pertain to these outcomes. Pierrakos, Borrego, and $\mathrm{Lo}^{3,4}$ used these fifteen criteria to construct a 50-item instrument capable of measuring students' perceptions of their technical and professional learning outcomes. Technical learning outcomes include engineering subject matter knowledge generally focused on the application of mathematics, science, and design concepts. Professional learning outcomes are personal skills such as communication, teamwork, and lifelong learning. Items on the National Engineering Students' Learning Outcomes Survey (NESLOS) were written to assess knowledge and skills pertaining to, but not limited to: (1) problem-solving, (2) writing and communication skills, (3) understanding and applying knowledge, (4) teamwork, (5) confidence gains, (6) organization and management skills, and (7) interest and engagement of project.

Two studies were conducted by Pierrakos, Borrego, and Lo using NESLOS to look at desired engineering learning outcomes gained from mechanical engineering senior design projects and cooperative (co-op) experiences. Students completed NESLOS to record how helpful the experience was in enabling them to achieve the technical and professional skills by ranking the fifteen engineering learning outcomes. Senior mechanical engineering students participating in a senior capstone project were shown to ascribe high value to the learning outcomes of the experience. Personal and professional skill gains were ranked higher than their technical outcomes with female students having statistically higher scores than their male classmates. Engineering co-op students (mostly rising seniors) revealed that a co-op experience was also highly valued overall with females rating the five most highly ranked outcomes (all professional skills) significantly higher than their male classmates. 
While these two contexts are not service experiences, the research provides evidence that student self-reported sources of learning can be associated with a particular type of learning experience. This can serve as an indicator for whether a novel learning experience provides a unique opportunity for novel learning outcomes. The general approach to measuring student perceptions is important in framing our study on students. It was also noted by the authors that NESLOS,

"[...] can be useful to other engineering disciplines and learning experiences, such as research, coursework, and service learning experience, as well.".3

\section{Research Methods}

\section{Sample}

We used a nationwide sample of students participating in various forms of engineering service efforts across the United States. Participants were recruited through professors, program managers, and student officers of recognized service courses and programs. Initial recruitment reached out to more than 1000 students from over 100 institutions across the United States. The final sample consisted of 322 unique undergraduate and graduate student responses hailing from 87 different institutions representing in-class service-learning, extracurricular service groups, and $\mathrm{K}-12$ outreach programs. The number of students representing a program varied from two to twenty. Some responses obtained during data collection were excluded from analysis because the student did not complete the entire survey, entered the survey multiple times, or rated each item with the same score across a given scale.

The 322 students used for the study ranged in age from 18 to 45 years old with a mean $(M)$ of 21.4 and a standard deviation of 3.8. Their experience within a given service program ranged from one to eight years $(M=2.0 \pm 1.2)$. Some students did identify themselves as participants in multiple service experiences. Students included first-years $(n=30)$, sophomores $(n=54)$, juniors $(n=66)$, seniors $(n=111)$, and graduate students $(n=44)$. The overall sample consisted of individuals majoring in a variety of engineering disciplines including civil $(n=63)$, mechanical $(n=63)$, environmental $(n=43)$, chemical $(n=31)$, biomedical/bioengineering $(n=30)$, materials/materials science $(n=27)$, and electrical $(n=16)$. The majority of the students were Caucasian $(\sim 77 \%)$ and the sample consisted of 161 females and 161 males.

\section{Instrument Design}

A modified-NESLOS was developed for the purpose of analyzing the impact of engineering service opportunities. Modifications were made to reduce the length of the survey, to validate the instrument, and to provide students with an opportunity to compare the impact of their service experience with the impact of their other engineering coursework.

First, the instrument was reduced from fifty items to sixteen to reduce the time to complete the survey. Sixteen items were deemed the minimum number of items necessary to ensure that each of the key technical and professional skills identified in the ABET 3a-k criteria outcomes and NAE CASEE report were still included. The scale was then changed to a 10-Likert scale from zero to 100 rather than a 5-point Likert scale, because it is a stronger predictor of performance 
and students, the population of interest, have a comfort level in being scored in school on a 100point scale. ${ }^{5}$ Finally, the scale was modified in order to identify the impact of their service experience(s) relative to their traditional (i.e., non-service-learning) coursework simultaneously. This was accomplished with a double-sided scale where the extremes represent $100 \%$ for one intervention and $0 \%$ for the other intervention

Example: $10 \mathrm{CL} / 90 \mathrm{SE}=10 \%$ from coursework learning/90\% from service experience

A student who chooses the 50CL/50SE option holds the perception that their service experience and their traditional coursework learning have equally accounted for their attainment of the given skill. An option of "I already had that skill" was also included to allow students to make the claim that they learned the particular skill from something other than their service or traditional coursework.

The final modified-NESLOS (Appendix I) consisted of 16-items developed and used to investigate students' perceptions of the impact of their service experience compared to traditional coursework on learning technical (six items) and professional skills (nine items).

\section{Results}

Previous studies employing the original NESLOS instrument did not validate the instrument or the results. The American Educational Research Association, American Psychological Association, and National Council on Measurement in Education recommends content validity as the source of validity evidence concerning the extent to which a measurement adequately samples a specific domain represented in an instrument. ${ }^{6,7,8,9}$ For this study, content validity was used to show how well the items based on the ABET Criteria 3a-k and NAE CASEE report adequately represented the chosen domain, engineering learning outcomes.

Factor analysis was used to provide content validity evidence and/or support. Factor analysis produces factor-weighted scores for each of the identified dependent variables. The factorweighed scores tabulated as $z$-scores were determined by transforming students' raw scores across a number of items loaded to a factor. $z$-scores are calculated by subtracting the sample mean from each person's score and dividing it by the standard deviation of the entire sample.

To ensure that the modified-NESLOS instrument used for this study was valid, confirmatory factor analysis was conducted to identify the number of underlying factors that existed among the sixteen items used. This process is undertaken to provide evidence that each given item represents its desired purpose. Factor analysis produced two distinct factors - 1) technical skills $(T S)$ consisting of six items; and 2) professional skills (PS) consisting of ten items - determined using only factors with eigenvalues greater than one. ${ }^{10}$ In essence this means that technical skills can be measured based on a factor score influenced by six items and professional skills can be measured based on a factor score influenced by ten items. The items that loaded to each factor can be seen in Table I. Factor loadings, or correlation coefficients between each variable and a given factor, were included only when above 0.3 . Values less than 0.3 were completely removed from the analysis. Significant factor loadings were all greater than 0.6 with no significant crossloadings. 
Reliability of each dependent variable was shown with inter-item reliability coefficients (Cronbach's $\alpha$ ) among the items loaded to each factor. Criteria to judge reliability were as follows: $\alpha$ greater than 0.9 was excellent, between 0.8 and 0.9 was good, between 0.7 and 0.8 was acceptable, between 0.6 and 0.7 was questionable, between 0.5 and 0.6 was poor, and below 0.5 was unacceptable. ${ }^{11}$ The Cronbach's $\alpha$ values for PS (0.910) and TS (0.848) showed an excellent reliability for the two factors suggesting that scores across items in a given factor were consistent, repeatable, and reliable.

Table I. Factor loadings for the modified-NESLOS items.

\begin{tabular}{|c|c|c|}
\hline Item & $T S$ & $P S$ \\
\hline 1. Apply math, science, and engineering knowledge. & 0.635 & \\
\hline 2. Communicate effectively with others. & & 0.799 \\
\hline 3. Operate in the unknown (i.e. open-ended design problems). & & 0.793 \\
\hline 4. Function within a team & & 0.781 \\
\hline 5. Engage in critical, reliable, and valid self-assessment (i.e. reflection). & & 0.727 \\
\hline 6. Persevere to complete an engineering design task. & & 0.767 \\
\hline 7. Maintain a strong work ethic throughout an engineering design project. & & 0.743 \\
\hline 8. Design a system, component, or process to meet desired needs. & 0.743 & \\
\hline 9. Understand the impact of your engineering design/solution in a societal and global context. & & 0.769 \\
\hline 10. Design an experiment. & 0.797 & \\
\hline 11. Analyze and interpret data. & 0.797 & \\
\hline 12. Identify potential ethical issues and dilemmas of a project. & & 0.737 \\
\hline 13. Apply techniques, skills, and modern engineering tools in practice. & 0.747 & \\
\hline 14. Conduct (or simulate) an experiment. & 0.806 & \\
\hline 15. Recognize the need for life-long learning. & & 0.692 \\
\hline 16. Knowing what you want to do after graduation (get a job, go to graduate school, etc...) & & 0.639 \\
\hline
\end{tabular}

\section{Discussion}

The modified-NESLOS instrument was shown to be a valid and reliable way to measure student perceptions of service on learning technical and professional skills. Many factors went into the creation of this instrument that will be discussed here. First, the original effort to measure service as a source of learning was going to use the fifty item NESLOS instrument. Issues were immediately apparent when it was noted that no validity or reliability testing had been published by previous studies. This, compacted with the length of the instrument, prompted us to investigate modifying and further testing the instrument.

Without the previous data, it is impossible to know if the original instrument and the results were valid. Our testing therefore began at a base level. Content-wise it was positive to find that those criteria identified by ABET and the NAE CASEE Report matched well with our hypothesized TS and PS factors. Items did not significantly cross-load, revealing two very distinct learning outcome factors in engineering. The reliability of the two factors further confirms the substantial nature of the two factors. 
Beyond the validation of the instrument, it is interesting to take a quick glance at the scores of the 322 service students. ${ }^{12}$ The results suggest that a service experience relative to traditional coursework has a substantial impact on their learning of both technical and professional skills. Students identified that 34 percent of what they learned about technical skills and 45 percent of what they learned about professional skills was learned through their service activity. While traditional coursework learning was identified to have a larger impact for both domains, the relative time spent on service compared to traditional coursework suggests service to be an important experience in this cohort of students' engineering education. The impact was identified to be even more important for females who identified significantly higher perceptions of service as a source of learning compared to their male classmates. Scores were consistent across academic years.

\section{Conclusions and Implications}

The modified-NESLOS instrument was successfully tested and shown to be a valid and reliable way to analyze how students perceive service experiences impacting their learning of technical and professional skills. The analysis was framed as a comparison of service implications verse traditional coursework learning. The approach taken can be used to compare the impact of any two interventions against one another. The information gathered provides solid feedback toward understanding what pedagogical methods students believe to be most impactful on their learning. The results of such studies should further the development of new curricula and the integration of new pedagogical approaches.

\section{Acknowledgements}

This material is based upon work supported by the National Science Foundation under Grant No. 0835981. Any opinions, findings, and conclusions or recommendations expressed in this material are those of the author(s) and do not necessarily reflect the views of the National Science Foundation.

\section{Bibliography}

1. Accreditation Board for Engineering and Technology. (1999). Criteria for accrediting engineering programs: The Engineering Accreditation Commission of the Accreditation Board for Engineering and Technology.

2. Bjorklund, S., \& Fortenberry, N. L. (2005). Final report: Measuring student and faculty engagement in engineering education. Center for the Advancement of Scholarship on Engineering Education (CASEE): National Academy of Engineering.

3. Pierrakos, O., Borrego, M., \& Lo, J. (2007). Assessing learning outcomes of senior mechanical engineers in a capstone design experience. Paper presented at the American Society for Engineering Education Annual Conference \& Exposition, Honolulu, HI.

4. Pierrakos, O., Borrego, M., \& Lo, J. (2008). Preliminary findings from a quantitative study: What are students learning during cooperative education experiences? Paper presented at the American Society for Engineering Education Annual Conference \& Exposition. 
5. Pajares, F., Hartley, J., \& Valiante, G. (2001). Response format in writing self-efficacy assessment: Greater discrimination increases prediction. Measurement and Evaluation in Counseling and Development, 33, 214-221.

6. American Educational Research Association, American Psychological Association, and National Council on Measurement in Education. (1999). Standards for educational and psychological testing. Washington, DC: American Educational Research Association.

7. Carminer, E. G., \& Zeller, R. A. (1979). Reliability and validity assessment. Thousand Oaks, CA: SAGE Publications.

8. Messick, S. (1989). Validity. In R. L. Linn (Ed.), Educational Measurement (3rd ed., pp. 13-103). Washington, D.C.: The American Council on Education and the National Council on Measurement in Education.

9. Moskal, B. M., Leydens, J. A., \& Pavelich, M. J. (2002). Validity, reliability and the assessment of engineering education. Journal of Engineering Education, 91(3), 351-354.

10. Rummel, R. J. (1970). Applied factor analysis. Evanston, IL: Northwestern University Press.

11. George, D., \& Mallery, P. (2003). SPSS for Windows step by step: A simple guide and reference. 11.0 update (4th ed.). Boston: Allyn \& Bacon.

12. Carberry, A. R. (2010). Characterization Analysis of Engineering Learning-through-Service Students by Gender and Academic Year. Unpublished dissertation. Tufts University.

\section{Appendix I: Modified National Engineering Students' Learning Outcomes Survey (NESLOS)}

Directions: Rate how helpful your engineering service experience (SE) was compared to your coursework learning (CL) in enabling you to achieve the following skills.

Choose the option that best depicts the percent impact from engineering learning-through-service and coursework.

Ex. $10 \mathrm{CL} / 90 \mathrm{SE}=10 \%$ impact from coursework $/ 90 \%$ impact form engineering service experiences

$\begin{array}{ll}0 \mathrm{CL} / 100 \mathrm{SE} & 60 \mathrm{CL} / 40 \mathrm{SE} \\ 10 \mathrm{CL} / 90 \mathrm{SE} & 70 \mathrm{CL} / 30 \mathrm{SE} \\ 20 \mathrm{CL} / 80 \mathrm{SE} & 80 \mathrm{CL} / 20 \mathrm{SE} \\ 30 \mathrm{CL} / 70 \mathrm{SE} & 90 \mathrm{CL} / 10 \mathrm{SE} \\ 40 \mathrm{CL} / 60 \mathrm{SE} & 100 \mathrm{CL} / 0 \mathrm{SE} \\ 50 \mathrm{CL} / 50 \mathrm{SE} & \mathrm{I} \text { already had that skill (please list from where) }\end{array}$

1. Apply math, science, and engineering knowledge.

2. Design a system, component, or process to meet desired needs.

3. Design an experiment.

4. Analyze and interpret data.

5. Apply techniques, skills, and modern engineering tools in practice.

6. Conduct (or simulate) an experiment.

7. Communicate effectively with others.

8. Operate in the unknown (i.e. open-ended design problems).

9. Function within a team

10. Engage in critical, reliable, and valid self-assessment (i.e. reflection).

11. Persevere to complete an engineering design task.

12. Maintain a strong work ethic throughout an engineering design project.

13. Understand the impact of your engineering design/solution in a societal and global context.

14. Identify potential ethical issues and dilemmas of a project.

15. Knowing what you want to do after graduation (get a job, go to graduate school, etc...)

16. Recognize the need for life-long learning 